\title{
Traffic restrictions in Beijing during the Sino-African Summit 2006: aerosol size distribution and visibility compared to long-term in situ observations
}

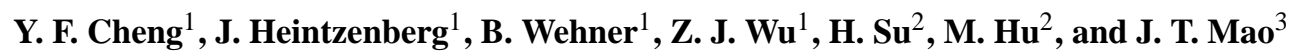 \\ ${ }^{1}$ Leibniz-Institute for Tropospheric Research, 04318 Leipzig, Germany \\ ${ }^{2}$ State Key Joint Laboratory of Environmental Simulation and Pollution Control, College of Environmental Sciences and \\ Engineering, Peking University, Beijing 100871, China \\ ${ }^{3}$ Department of Atmospheric Physics, School of Physics, Peking University, Beijing 100871, China
}

Received: 15 April 2008 - Published in Atmos. Chem. Phys. Discuss.: 9 July 2008

Revised: 7 October 2008 - Accepted: 9 October 2008 - Published: 17 December 2008

\begin{abstract}
Based on the long-term in-situ observations of aerosol particle number size distributions and meteorological parameters, the measures of traffic restriction during the Sino-African Summit (4-6 November 2006) in Beijing, China have been found to be efficient in reducing the number concentration of aerosol particles, in particular Aitken and accumulation mode particles, and in improving the visibility when local emissions dominated. The influence of traffic restrictions on the particle concentrations differed for different particle sizes. More significant effects on fine particles with diameters ranging from 40 to $500 \mathrm{~nm}$ have been found. Based on statistical analysis of long-term observations, under comparable weather conditions, the number concentrations of the particles in Aitken and accumulation modes seemingly were reduced by $20-60 \%$ when the traffic restrictions were in place. This change may be mainly due to the reduction of secondary particle contributions. However, it is worth to notice that the reduction of $60 \%$ might overestimate the effect of the measures of traffic control, due to the inherent data shortage with very high wind speeds in the comparison data population. Our size-dependent aerosol data also indicate that measures led to reductions in particulate air pollution in the optically most important diameter range, whereas further vehicle restriction measures might lead to an increase in ultrafine particle formation if the condensational sink further decreased. Assuming that there were no traffic restrictions and with normal levels of the vehicle emissions, the vis-
\end{abstract}

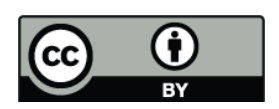

Correspondence to: J. Heintzenberg (jost@ tropos.de) ibilities during the Summit would have been lower by about $20-45 \%$. The fact that over $95 \%$ cases with visibility range lower than $5 \mathrm{~km}$ during 2004 to 2007 occurred when the local wind speed was lower than $3 \mathrm{~m} \mathrm{~s}^{-1}$ may suggest that the importance of the emission restrictions is highest when the wind speed is lower than $3 \mathrm{~m} \mathrm{~s}^{-1}$, concerning the improvement of serious low visibility situations in Beijing.

\section{Motivation}

Particles in the atmosphere arise from natural sources and from anthropogenic activities. They are emitted directly as particles or formed in the atmosphere by gas-to-particle conversions. A significant fraction of the tropospheric aerosol is anthropogenic in origin (Seinfeld and Pandis, 1998), in particular with diameters below one micrometer (fine particles) which result from nucleation/condensation of anthropogenic particle precursors or as directly emitted soot particles. Many urban regions face serious particulate pollution problems and their environmental agencies need to understand the most important aerosol sources before implementing clean-air measures.

A forward strategy in trying to understand the relationships between different pollution sources and air quality starts with information on emissions and then predicts the pollution by means of air quality models with different emission scenarios. An inverse research strategy uses the atmosphere as a natural laboratory to estimate the influence of different pollution sources by means of utilizing known changes in certain pollution sources with concurrent

Published by Copernicus Publications on behalf of the European Geosciences Union. 
measured changes in air quality. Changes in pollution sources may be inadvertent as in the case of the terrorist attacks on 11 September 2001 (Travis et al., 2002) or can be deliberate interventions affecting pollution sources such as in the Heilbronn experiment in June 1994 where during four days traffic restrictions were enacted in search of measurable changes in ozone levels (Moussiopoulos et al., 1997).

Concomitant with its fast economic development, severe aerosol pollution in China has attracted global attention. Beijing, the capital of China, is one of the largest mega cities in the world, with approximately 17 million inhabitants and over 3.2 million motor vehicles to date $(\sim 5 \%$ diesel vehicles in 2004; Xie et al., 2008). Any efforts to improve the air quality of Beijing will require a clear understanding of the potential sources of particles. Traffic emissions are considered to be one of the most important sources of sub-micrometer particles in the urban area of Beijing (Zhang and Shao, 1997; He et al., 2001; Zheng et al., 2005; Song et al., 2006 etc.). Zheng et al. (2005) and Song et al. (2006) indicated that, as a primary source, traffic emissions in Beijing contributed 6-7\% to particulate mass concentrations below $2.5 \mu \mathrm{m}\left(\mathrm{PM}_{2.5}\right)$. The respective contribution from road dust resuspension was estimated to be 7-9\%. However, gaseous pollutants are also emitted by vehicular sources, such as $\mathrm{NO}_{\mathrm{x}}$ and organic compounds, which are essential for the atmospheric photochemical processes and the gas-to-particle conversions. The latter are closely related to the formation of secondary particulate matter. In total, secondary ammonium, sulfate and nitrate contributed over $35 \%$ of $\mathrm{PM}_{2.5}$ in Beijing (Zheng et al., 2005; Song et al., 2006). However, this percentage did not include the contribution of secondary organic particles. Zheng et al. (2005) reported that particulate organic matter accounted for over $50 \%$ of $\mathrm{PM}_{2.5}$ in the urban area of Beijing during winter time, of which less than $30 \%$ might be explained by biomass burning (Duan et al., 2004).

A specific and mandatory rehearsal of the traffic control strategies, instituted by the Beijing municipal authorities as part of the preparations for the Olympic Games, was conducted in Beijing during 4 to 6 November 2006 in connection with the Summit of the Forum on China-Africa Cooperation (4 and 5 November 2006). News reports on China Daily (2006) suggested that approximately 30\% ( 800 000) of the cities' 2.8 million vehicles were taken off the roads as a result of measures adopted during the Summit by the Beijing municipal authorities. This rehearsal offers an interesting opportunity to improve our understanding of the complex relationship between emission sources and the concentration level of major atmospheric pollutants in a realistic "natural atmospheric chamber".

Wang et al. (2007) reported that this event was successful with about $40 \%$ reduction in associated emissions of $\mathrm{NO}_{\mathrm{x}}$. However, their result was based on satellite remote sensing of columnar atmospheric properties $\left(\mathrm{NO}_{2}\right.$ column density) and a 3-dimensional chemical transport model, but lacked in-situ observations, in particular any aerosol data, which are of prime interest with respect to visibility. Also no specific local meteorological parameters were taken into account. In the present study, we analyze the influence of the Summit traffic restrictions on the aerosol size distribution and visibility based on long-term in situ observations as well as meteorological monitoring data in Beijing.

\section{Long-term observations of particle number size dis- tributions in Beijing}

Since 2004, long-term measurements of aerosol particle number size distributions have been conducted at a site $(20 \mathrm{~m}$ above the ground level) on the campus of Peking University (PKU site, $\left[39.99^{\circ} \mathrm{N}, 116.31^{\circ} \mathrm{E}\right]$ ). The campus is located in the northwestern urban area of Beijing, China. Wehner et al. (2008) indicated that an earlier examination of the spatial variability of $\mathrm{PM}_{2.5}$ mass and chemical composition in 1999 2002 showed only minor differences between the PKU site and a downtown site, which has also been reported by He et al. (2001). Consequently, the PKU site had been considered to be representative for the Beijing urban environment.

Particles are sampled with a low-flow $\mathrm{PM}_{10}$ impactor inlet. Particle number size distributions with electric mobility diameter from three to $800 \mathrm{~nm}$ are scanned with a Tandem Differential Mobility Particle Sizer (TDMPS) (Birmili et al., 1999). At the same time, an Aerodynamic Particle Sizer (APS, TSI 3321) is used to measure the particle number size distributions with aerodynamic diameters from $800 \mathrm{~nm}$ to $10 \mu \mathrm{m}$. The relative humidity within the combined system of TDMPS and APS is kept below 30\% (Birmili et al., 2004) by adding dryers based on Nafion membrane technology and also silica-gel diffusion-dryers in the aerosol inlet flow and the sheath air flow. The system flow rates are checked manually once per week. Aerodynamic diameters measured with the APS have been converted to Stokes diameters by dividing by the square root of a density of dry particles as $1.7 \mathrm{~g} \mathrm{~cm}^{-3}$ (Wehner et al., 2004; Wu et al., 2007, 2008). Corrections considering diffusional and gravitational losses in the sampling system have been applied according to Willeke and Baron (1993). The time resolution of the particle number size distributions, combined with TDMPS and APS data, is $10 \mathrm{~min}$.

A meteorological station is operated simultaneously to monitor meteorological parameters, including wind speed (WS), wind direction (WD), relative humidity (RH), air temperature $(T)$, and air pressure $(P)$. This station is about $400 \mathrm{~m}$ away from the PKU site and is mounted on top of a $20 \mathrm{~m}$ high building.

\section{Aerosol variability in fine and coarse mode during the Summit period}

Figure 1 presents the different patterns of size-dependent particle numbers measured at the PKU site in October and 

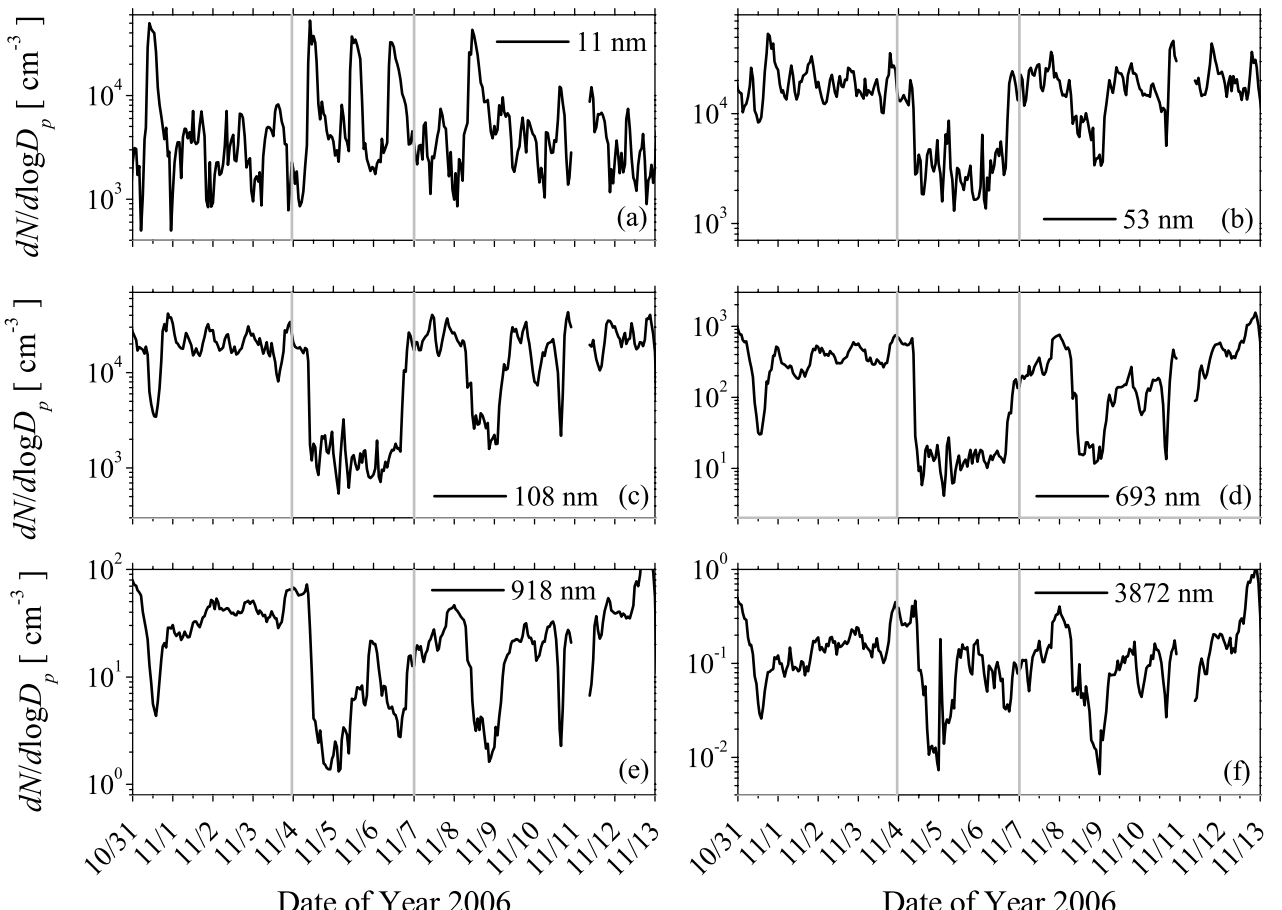

Date of Year 2006

Fig. 1. Time series of particle numbers at different diameters in October and November 2006 at the PKU site on the campus of Peking University, Beijing.

November 2006. While the public had been advised to drive less for six days (1 to 6 November 2006), specific and mandatory regulations were instituted only between 4 to 6 November 2006 (Wang et al., 2007). Thus this traffic restrain period will be referred as "Summit" period in the following text. A notable feature of Fig. 1 is the significant reduction of aerosol particles as a function of particle size in Beijing during 4 to 6 November 2006, compared to the time before and after. These changes coincided with the traffic restrictions instituted during the Summit. It should be noted that the Summit period (4-6 November 2006) occurred on a weekend (Saturday-Monday). However, Fig. 1 includes additional weekend days 11-12 November. Nevertheless, no obvious "weekend effect" was found.

The aerosol exhibited a size-dependent variability during the Summit period. Figure 1 shows that the number concentrations of Aitken mode and accumulation mode particles with diameters from about 50 to $800 \mathrm{~nm}$ mostly stayed very low, while this was not the case for the nucleation mode (smaller than $30 \mathrm{~nm}$ ) and coarse mode (larger than $1000 \mathrm{~nm}$ ) particles.

There was no obvious influence on the number concentrations of nucleation mode particles (e.g., $11 \mathrm{~nm}$ in Fig. 1) by the traffic restrictions. Instead of decreasing they actually increased in the mornings and early afternoons during the Summit period when the wind speed was higher than 6$8 \mathrm{~m} \mathrm{~s}^{-1}$ (cf. Fig. 1 and Fig. 2). Wehner et al. (2004) indicated that new particle formation events in Beijing tended to occur when the total particle surface decreased and the condensational sink was low. Wu et al. (2007) analyzed the new particle formation events at the PKU site for the year 2004. Their results show that when the air mass arrived in Beijing from the north or northwest the formation events generally occur when the local wind speeds are steadily higher than 6 $8 \mathrm{~m} \mathrm{~s}^{-1}$ with a condensational sink lower than $0.02 \mathrm{~s}^{-1}$. In Beijing, as in most urban environments, the particle surface concentration is dominated by accumulation mode particles (Wu et al., 2008).

Concurrent with the nucleation mode increase we thus see a sharp reduction in number concentrations of the Aitken and accumulation mode particles (e.g., 53, 108, $693 \mathrm{~nm}$ in Fig. 1), coinciding with the traffic restrictions instituted during the Summit. Comparing the fine and coarse mode particles, the major difference was that the reduction of coarse mode particle numbers was not as constant as in the accumulation mode during the Summit. After 5 November, the number concentration of coarse mode particles increased with increasing north/northwest wind (cf. Figs. 1e-f and 2a-b). The primary particles emitted directly from the vehicles are dominated by the fine particles with diameters below $500 \mathrm{~nm}$ and peaking at around 40 to $100 \mathrm{~nm}$ (Wehner et al., 1999, 2002; Wehner and Wiedensohler, 2003; Janhäll et al., 2004; Imhof et al., 2006; Rose et al., 2006). Also nucleation/condensation of vehicle emitted particle precursors mostly contribute to the concentration of particles at diameters below one micrometer (fine particles). It may indicate that the traffic restrictions 

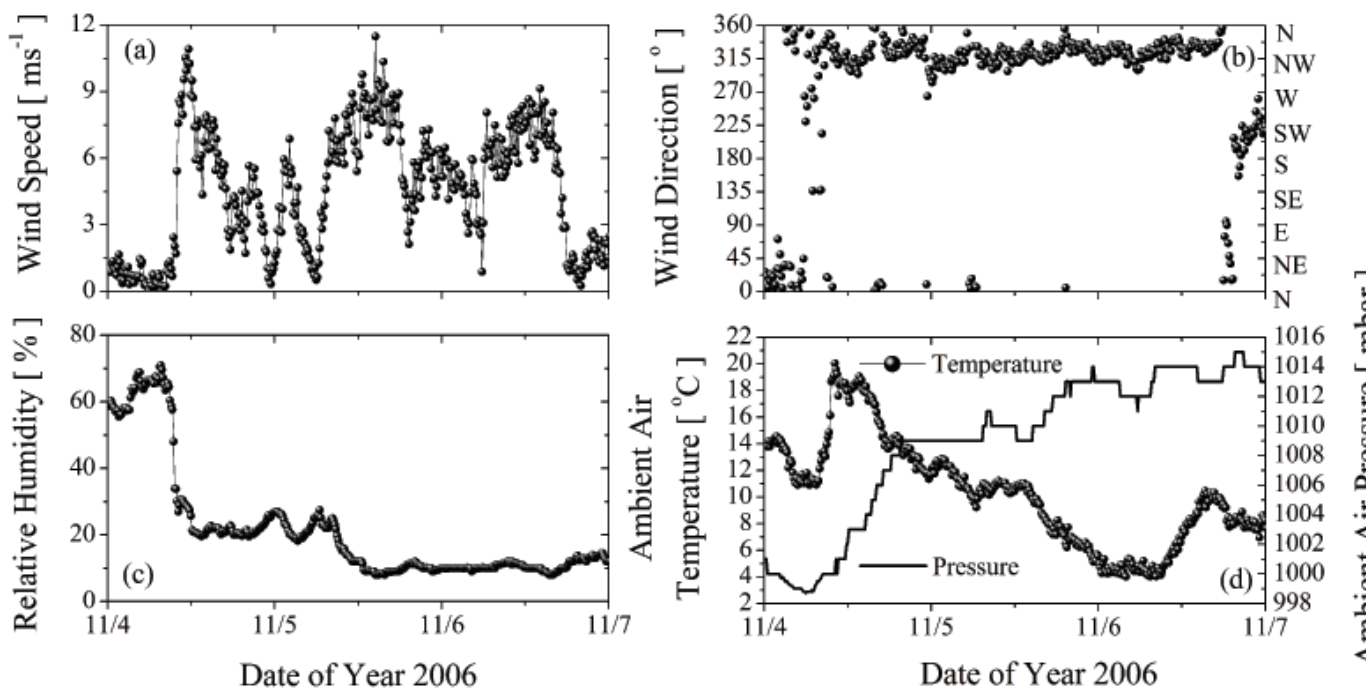

Fig. 2. Local meteorological parameters include wind speed (a), wind direction (b), relative humidity (c), and ambient air temperature and pressure (d) near the PKU site during the Summit period (4 to 6 November 2006). The time resolution of the presented data sets is $1 \mathrm{~h}$.

were more effective concerning fine than coarse particles.

In the next section, we will relate this reduction to synoptic, seasonal, and long-term aerosol changes according to the long-term aerosol records in Beijing, which will provide a general statistical quantification of this reduction.

\section{Statistical comparisons of Summit and non-Summit periods}

The temporal variability of particle number concentrations reflects a combination of changes in emissions, meteorological conditions, and secondary formation of particulate matter. As indicated by $\mathrm{Wu}$ et al. $(2007,2008)$ and Wehner et al. (2008), the level of particulate pollution in Beijing strongly depends on the meteorological conditions, especially the local wind speed and direction. This means that we cannot simply compare the pollution level during Summit with the pollution level before and after.

According to the recorded meteorological data, there were obvious changes in the local meteorological conditions before, during, and after the Summit period. Figure 2 shows the time series of the measured local meteorological parameters. In the week before the Summit period, average ambient $T$ and $\mathrm{RH}$ were about $18^{\circ} \mathrm{C}$ and $55 \%$, respectively, i.e., much higher than respective values during the Summit pe$\operatorname{riod}\left(\sim 10^{\circ} \mathrm{C}\right.$ and $\left.21 \%\right)$. During Summit traffic restrictions, north/northeast wind dominated $91 \%$ of the time, and the wind speed varied from calm wind to $10-12 \mathrm{~m} \mathrm{~s}^{-1}$, whereas before and shortly after Summit, the wind speed stayed at 0.5 to $4 \mathrm{~m} \mathrm{~s}^{-1}$. One may suspect these strongly varying meteorological conditions to have been the main cause of the reduction in particle concentrations during the Summit period.
In order to segregate possible meteorological effects and to quantify approximately the influence of the traffic restriction measures on aerosol size distributions and visibility, the long-term observational data were used. However, one should only compare the particle size distributions during Summit with those with similar source conditions (except vehicle emissions), under similar local meteorological conditions, and with similar regional air mass transport characteristics. The criteria for selecting the comparable data population, named as "non-Summit" period, are described in the following.

\subsection{Source conditions}

In general, residential heating in Beijing starts in the beginning of November and ends by the end of March. According to the statistical analysis of the long-term particle size distributions, there are significant aerosol differences in March, compared to November, December, January and February. Particle number concentrations are generally higher and dust events occur more frequently in March. An inspection of the data showed that, even if November, December, January and February all were considered in the non-Summit reference data population, the data of November would dominate the selected data population due to the other criteria described later, e.g., the temperature criterion. Moreover, gasto-particle conversions, including photochemical secondary particle formation and condensation, are considered major sources of urban aerosol particles. The solar zenith angle and incident radiation are different at different times of year. In order to have similar photochemical and radiation conditions, a conservative decision was made to choose only data measured in the Novembers of 2004, 2005, 2006 (three months, excluding the summit period). 
Table 1. Criteria local meteorological conditions and distance to the mean back trajectory of Summit period.

\begin{tabular}{llllll}
\hline Wind Direction & & $\begin{array}{l}\text { Relative } \\
\text { Humidity }\end{array}$ & $\begin{array}{l}\text { Ambient } \\
\text { Temperature }\end{array}$ & $\begin{array}{l}\text { Ambient Air } \\
\text { Pressure }\end{array}$ & $\begin{array}{l}\text { Distance to the } \\
\text { mean Back } \\
\text { Trajectories }\end{array}$ \\
\hline $0^{\circ}-60^{\circ}$ & Lower Limit $^{\mathrm{a}}$ & $9 \%$ & $4.4^{\circ} \mathrm{C}$ & $999.2 \mathrm{mbar}$ & 0 \\
$300^{\circ}-360^{\circ}$ & Upper Limit $^{\mathrm{a}}$ & $60 \%$ & $18.2^{\circ} \mathrm{C}$ & $1014.2 \mathrm{mbar}$ & 72.0 \\
\hline
\end{tabular}

a The lower and upper limits are taken as $5 \%$ and $95 \%$ quantile of respective data during the Summit periods.

\subsection{Local meteorological conditions}

Only local weather conditions dominated by northern (northeast through northwest) wind directions were considered both in Summit and non-Summit periods, because northern wind frequency was about $91 \%$ during the Summit period. Moreover, the data in November 2004, 2005, 2006 were also selected within the $90 \%$ ranges of the other meteorological parameters during the Summit time periods (10\% extreme cases were excluded, cf. Table 1). The criteria for local meteorological conditions are summarized in Table 1.

However, we also realized that there could be the situation that our classification just selected continuously calm/low winds, e.g., $0-3 \mathrm{~ms}^{-1}$, while the slow winds followed the strong winds or were in between during the Summit (cf. Fig. 2). It is reasonable that the particle number concentrations may be different between the continuously stagnant weather conditions and the low wind conditions after a pollutant removal process with strong winds, even though wind speeds in both situations were low. Based on a 2-year observational record, Wu et al. (2008) statistically analyzed the correlation between wind speed and the particle volume concentration. As shown in Fig. 8 of Wu et al. (2008), the removal efficiency of fine particles, especially the accumulation mode particles, kept nearly constant when the wind speed was higher than $\sim 4 \mathrm{~ms}^{-1}$. So, we did an additional filtering on the selected non-Summit data set. The low wind speed data point (e.g., $0-3 \mathrm{~m} \mathrm{~s}^{-1}$ ) would only be kept if within $24 \mathrm{~h}$ there had been a strong wind period (with wind speed greater than $4 \mathrm{~m} \mathrm{~s}^{-1}$, which satisfied the other non-Summit criteria as well) before. Therefore, the low wind speed data points and strong wind speed ones during the nonSummit periods were also connected.

\subsection{Air mass transport characteristics}

The $144 \mathrm{~h}$ back trajectories at $500 \mathrm{~m}$ at every hour in November 2004, 2005, and 2006, calculated with NOAA Hysplit model (Draxler and Rolph, 2003), were also considered as an additional criterion. First, the mean back trajectory during Summit period (latitude $\overline{\boldsymbol{X}}_{\text {Summit }}$, longitude $\overline{\boldsymbol{Y}}_{\text {Summit }}$ and elevation $\left.\overline{\boldsymbol{Z}}_{\text {Summit }}\right)$ was calculated. The distances $\left(D_{i}\right)$ of individual back trajectories of Summit period and of nonSummit periods $\left(\boldsymbol{X}_{\boldsymbol{i}}, \boldsymbol{Y}_{\boldsymbol{i}}\right.$ and $\left.\boldsymbol{Z}_{\boldsymbol{i}}\right)$ to the mean back trajectory of Summit were evaluated. For each back trajectory hour $j$, the spherical angular distance $\left(\xi_{i}^{j}\right)$ can be calculated as

$$
\begin{aligned}
\xi_{i}^{j}= & \arccos \left[\sin X_{i}^{j} \cdot \sin \bar{X}_{\text {Summit }}^{j}+\cos X_{i}^{j} \cdot \cos \bar{X}_{\text {Summit }}^{j}\right. \\
& \left.\cdot \cos \left(\bar{Y}_{\text {Summit }}^{j}-Y_{i}^{j}\right)\right] .
\end{aligned}
$$

The distance between two corresponding back trajectory points at hour $j$ is

$d_{i}^{j}=\left\{\left(w_{\xi} \cdot \xi_{i}^{j}\right)^{2}+\left[w_{Z} \cdot\left(Z_{i}^{j}-\bar{Z}_{\text {Summit }}^{j}\right)\right]^{2}\right\}^{\frac{1}{2}}$.

Here $w_{\xi}$ and $w_{Z}$ are the respective weighing factors of $\xi_{i}^{j}$ and the difference of $Z_{i}^{j}$ and $\bar{Z}_{\text {Summit }}^{j}$. The weighing factors were used because of different units of and $\xi_{i}^{j}$ and $Z_{i}^{j}$. In the present study, $w_{\xi}$ and $w_{Z}$ were respectively chosen as 1 and $6.31 \times 10^{-4}$, which were determined empirically by a sensitivity study in this air mass cluster analyses to distinguish better the different particle number size distributions (Engler et al., 2007). Finally, the total distance between two back trajectories was determined as a summation of distance at each hour with linearly decaying weighing factors $\left(u_{j}\right)$. This means that the nearest (regarding to the backward time) back trajectory point was the most important, whereas the further in backward time, the less the importance to the current concentration in Beijing was in our calculation.

$D_{i}=\sum_{j=1}^{j=144} u_{j} \cdot d_{i}^{j}, \quad u_{j}=1-(j-1) \cdot \frac{1-0.2}{144-1}$

The $95 \%$ quantile of the distances between back trajectories during Summit period to their mean trajectory is about 72. So, only data during non-Summit were chosen when the distance of its back trajectory to the mean back trajectory of Summit was smaller than 72 . The average distances of Summit and non-Summit periods to the mean back trajectory were about 42 and 45, respectively. Therefore, we concluded that characteristics of the long-range or regional air mass transport during Summit and non-Summit data sets were generally similar. 

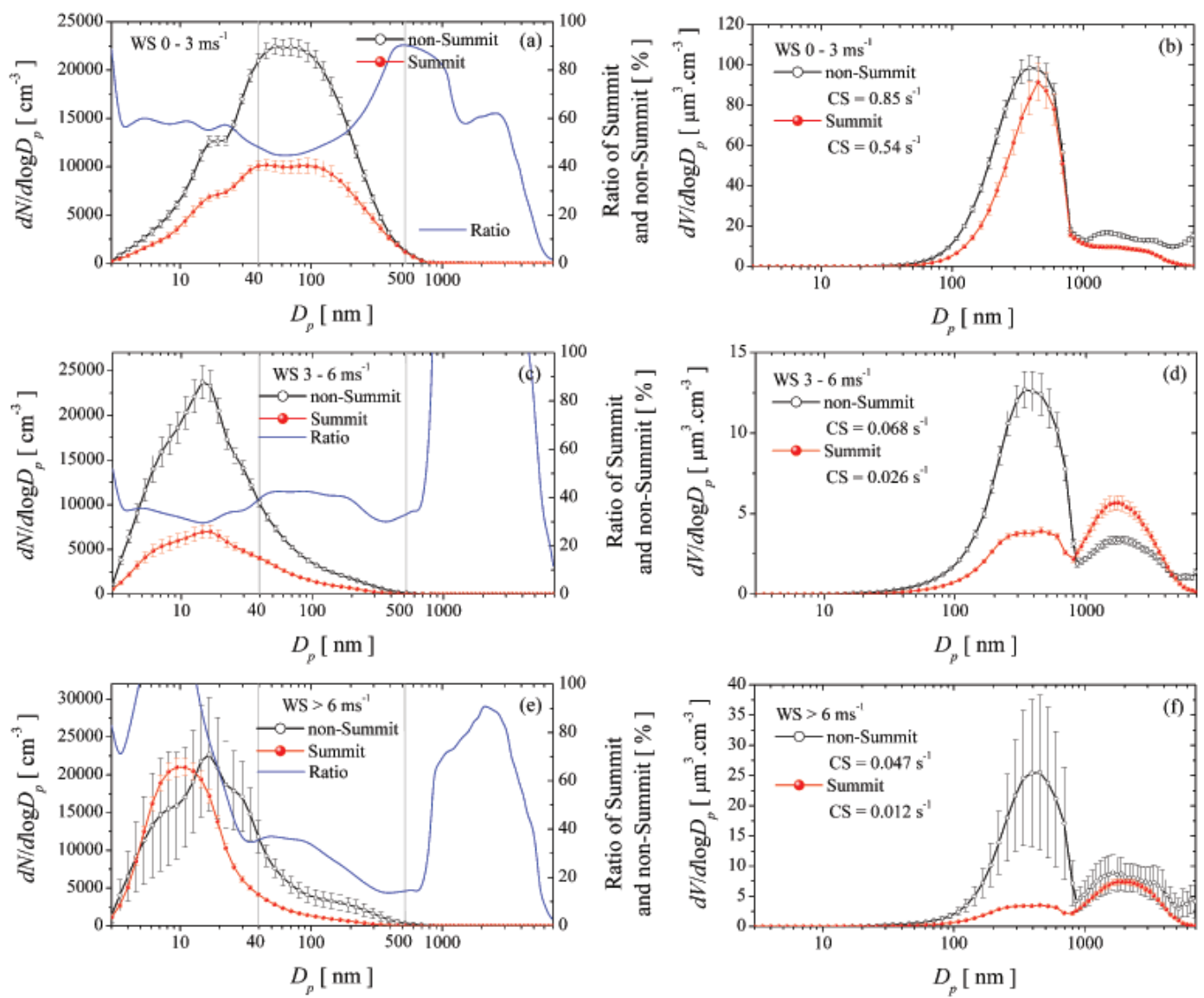

Fig. 3. Comparison of aerosol particle number and volume size distributions for Summit and non-Summit periods. The data are sorted by the local wind speed. Standard deviations about the mean values are given as error bars. The average condensational sinks (CS) are also given.

According to these criteria, a statistically comparable data population was formed with similar emissions (except vehicle emissions) and under similar local and regional meteorological conditions compared to the Summit period. This newly formed data population was denoted as "nonSummit". As we presented in Fig. 1, long-term statistical analysis also does not support any "weekend effect" on particle number size distributions in Beijing (Wu et al., 2008). Previous studies, e.g., Xia et al. (2008), did not either find clear weekly cycles of aerosol optical depth over Eastern China. So on weekdays and weekends the same criteria were applied for the two data populations. After the overall selections, there were 376 and 443 data points in Summit and non-Summit periods, respectively. The time resolution was $10 \mathrm{~min}$.

\section{Influence of the traffic restriction measures on the aerosol size distribution}

Local wind speed is one of the most important meteorology parameters controlling the level of air pollution. Therefore, for both Summit and non-Summit periods, we segregated the data populations into three subgroups with wind speeds ranging from 0 to $3 \mathrm{~m} \mathrm{~s}^{-1}, 3$ to $6 \mathrm{~m} \mathrm{~s}^{-1}$ and larger than $6 \mathrm{~m} \mathrm{~s}^{-1}$, respectively. These wind speed ranges were selected according to the similarities of particle number size distributions within different wind speed ranges. The number of data points in each wind speed subgroup is presented in Table 2. For later discussions concerning the particle formation, the respective condensational sinks (CS) were also calculated for each subgroup with the measured particle number size distribution and ambient temperature and relative humidity, following Kulmala et al. (1998) and Pirjola et al. (1998).

Figure 3 presents the comparison of average particle number and volume size distributions in Summit and non-Summit periods, respectively. The data populations are sorted by the local wind speeds. Mean values and their standard deviations are given, too. Obvious discrepancies between these two data populations (Summit and non-Summit) can be seen. The statistical significance of the discrepancies between the means of the entire size distributions in each pair of subgroups were tested by a multivariate analysis of variance. The differences of the entire mean values of particle size distributions for the wind speed ranges of $0-3 \mathrm{~m} \mathrm{~s}^{-1}$ and 3-6 $\mathrm{m} \mathrm{s}^{-1}$ (cf. Fig. 3ad) were statistically significant at $99 \%$ confidence level with 
Table 2. Number of data points in each wind speed subgroup during Summit and non-Summit periods.

\begin{tabular}{lcccc}
\hline & Total & $0-3 \mathrm{~m} \mathrm{~s}^{-1}$ & $3-6 \mathrm{~m} \mathrm{~s}^{-1}$ & $>6 \mathrm{~m} \mathrm{~s}^{-1}$ \\
\hline Summit & 376 & 100 & 130 & 146 \\
non-Summit & 443 & 253 & 180 & 10 \\
\hline
\end{tabular}

dimension of the group means as 1 . When the wind speed was larger than $6 \mathrm{~m} \mathrm{~s}^{-1}$, the differences between Summit and non-Summit periods were not statistically significant due to the large variances and too few data points in non-Summit subgroup (cf. Table 2 and Fig. 3e-f). Thus the following discussion will mainly focus on the subgroups with wind speed lower than $6 \mathrm{~m} \mathrm{~s}^{-1}$.

As can be seen in Fig. 3a-d, within each different wind speed class, the shape of particle number size distributions of Summit and non-Summit periods were generally similar, especially for the sub-micrometer particles. The wind speed class of $0-3 \mathrm{~m} \mathrm{~s}^{-1}$ was the most important, because it best represented the Beijing local emissions and was less influenced by regional or long-range transport. The number size distributions of Summit and non-Summit periods both peaked around $60-100 \mathrm{~nm}$, whereas the maxima of volume size distributions were at around $400-500 \mathrm{~nm}$. Particles with diameters from 40 to $500 \mathrm{~nm}$ were considered to be most strongly influenced by the traffic emissions, due to both primary emissions and secondary photochemical formation, condensation and coagulation. In Fig. 3a, the diameter range of 40 to $500 \mathrm{~nm}$, the ratio of particle numbers during Summit and non-Summit periods varied from about $40 \%$ to $80 \%$. This means that with similar other emissions (except vehicle emissions) and under similar meteorology conditions, particle numbers in Aitken and accumulation modes went down by $20-40 \%$ during Summit period. Another interesting feature in Fig. 3a-b is that the number of coarse mode particles was also much lower during Summit compared with the nonSummit period. There might be two reasons for this phenomenon. First, since the wind speed was relatively low $\left(<3 \mathrm{~m} \mathrm{~s}^{-1}\right)$, coarse mode particles were mainly due to local dust resuspension. During Summit, approximately $30 \%$ $(\sim 800000)$ of the cities' 2.8 million vehicles were taken off the roads. This of course would result in a reduction of the resuspended road/street dust in Beijing. On the other hand, the idea of the Summit traffic restrictions was not only a rehearsal for the Olympics but also as a logistical support to make it easier for Summit participants to get around Beijing. It can be expected that for the latter purpose, the municipality would have made more efforts on the road/street cleaning as well as watering the road/street and the plants. These efforts would also contribute to reducing the resuspension of road dust.
When the wind speeds were 3 to $6 \mathrm{~m} \mathrm{~s}^{-1}$, particle number size distributions were significantly different from those of the lower wind speed class $\left(0-3 \mathrm{~m} \mathrm{~s}^{-1}\right)$, not only in terms of the shape of the distributions but also in absolute number concentrations. Accompanied by a substantial decrease of particle number and surface in Aitken and accumulation modes, a sharp increase of nucleation mode particles was found during both Summit and non-Summit periods. Nevertheless a constant ratio of the particles concentrations from 40 to $500 \mathrm{~nm}$ between Summit and non-Summit periods existed ( $\sim 40 \%)$, as shown in Fig. 3c-d. Also the particle number concentrations in the nucleation mode during Summit were about $40 \%$ of those during non-Summit period, while the condensational sinks decreased from 0.068 to $0.026 \mathrm{~s}^{-1}$. This might be explained by a reduction of gas phase emissions of vehicles, which were part of the precursors and essential for the atmospheric photochemical and particle formation, condensation and coagulation processes.

Comparing Fig. 3b-c and a-b, obvious increases of coarse mode particle numbers with increasing wind speed have been found both during Summit and non-Summit periods. This is consistent with the variations of coarse mode particles discussed in Sect. aerosol. However, the concentrations of coarse mode particles were higher during Summit than during non-Summit periods. The time series of particle size distributions were checked, and it was found that significantly higher particle concentrations in coarse mode occurred only in the late night and very early morning during Summit. This might be caused by some changes in the regional or long-range transports. In the wind class of $3-6 \mathrm{~m} \mathrm{~s}^{-1}$ during the Summit period, the higher particle concentration in the coarse mode mostly occurred during nighttime. During those periods, the air masses more originated from the northern direction from Beijing and subsided from about $2000 \mathrm{~m}$ within $40 \mathrm{~h}$.

As indicated before, the difference of particle numbers during Summit and non-Summit periods when the wind speed higher than $6 \mathrm{~m} \mathrm{~s}^{-1}$ was not statistically significant. However, shape and concentration level for coarse mode particles were very similar. This may indicate similar characteristics of regional or long-range air mass transport. Moreover, very high numbers of nucleation mode particles (mainly with diameters smaller than $10 \mathrm{~nm}$ ) were found during the Summit period (cf. Fig. 3e) when the wind speed was higher than $6 \mathrm{~m} \mathrm{~s}^{-1}$. The corresponding condensational sink was only about $0.012 \mathrm{~s}^{-1}$, i.e., lower than $0.02 \mathrm{~s}^{-1}$, the threshold for significant new particle formation events in Beijing when northerly wind dominated, suggested by Wehner et al. (2004) and Wu et al. (2007).

The reduction of particle emission and formation, especially in the Aitken and accumulation mode ranges, resulting from the decrease in vehicular traffic during the Summit (4-6 November 2006) provides an obvious explanation for the difference between the two data populations during Summit and non-Summit periods. The number concentration 
of the particles in Aitken and accumulation modes was reduced by $20-60 \%$ during the Summit period. However, there was no comparable number of strong wind speed data points in the non-Summit period. We inspected the complete data sets from Novembers of 2004, 2005 and 2006. Except for Summit period, strong winds with wind speeds higher than $6 \mathrm{~m} \mathrm{~s}^{-1}$ did not occur often. On the other hand, we tried to pick up continuous weather process. However, not enough strong winds $\left(>6 \mathrm{~m} \mathrm{~s}^{-1}\right)$ data points occurred and could be further included into the non-Summit period. Therefore, it is worth to notice that the reduction of $60 \%$ might overestimate the effect of the measures of traffic control, due to the inherent data shortage with very high wind speeds during the non-Summit period. As mentioned before in the motivation, in the urban area of Beijing, the primary emissions by vehicle sources contribute 6-7\% of $\mathrm{PM}_{2.5}$ mass while the secondary inorganic salts (secondary ammonium, sulfate and nitrate) contribute over $35 \%$ of $\mathrm{PM}_{2.5}$, and secondary particulate organic matter contributes over $50 \%$ to $\mathrm{PM}_{2.5}$ in Beijing during winter time. Vehicle emissions are one of the most important sources contributing the precursors of the gas-toparticle conversion process. Therefore, any traffic restriction in Beijing would reduce not only the primary particle emissions from vehicles, but also the secondary particle sources since the precursors of secondary particles would be reduced too. Moreover, the contribution of secondary particles to the total fine particles is not linearly correlated with the source strength of the precursors. However, when the concentrations of Aitken and accumulation mode particles decreased, the condensational sink of particles also decreased. This would favor the new particle formation (Wu et al., 2007). But at the same time, condensation and heterogeneous reactions on existing particle would be reduced leading in total to reduction in secondary particle contribution to the sub-micrometer aerosol during the traffic restrictions. Therefore, we attribute the $20-60 \%$ reduction in Aitken and accumulation mode particles during Summit period mainly to this reduction of secondary particle contributions.

As discussed above, if the reduction of particle number concentrations in Aitken and accumulation modes were mainly due to the reduction of the secondary particle contributions, this effect should be strong during the daytime. We separated the Summit and non-Summit data sets into daytime (7:00 to 19:00) and nighttime (19:00 to 07:00 of the following day) for the wind classes of $0-3 \mathrm{~m} \mathrm{~s}^{-1}$ and $3-$ $6 \mathrm{~m} \mathrm{~s}^{-1}$. There were not enough data in the wind class of $>6 \mathrm{~m} \mathrm{~s}^{-1}$ to do the same analysis. In each wind class, the shapes of fine particle number concentrations were similar during daytime and nighttime, whereas the fraction of coarse mode particles to the total particulate volume concentration was higher during nighttime, especially in the wind class of 3-6 $\mathrm{m} \mathrm{s}^{-1}$ during Summit period. Interestingly, during both Summit and non-Summit period the fine particle concentrations were similarly lower during nighttime compared to daytime. This is opposite to the general understanding of the di-
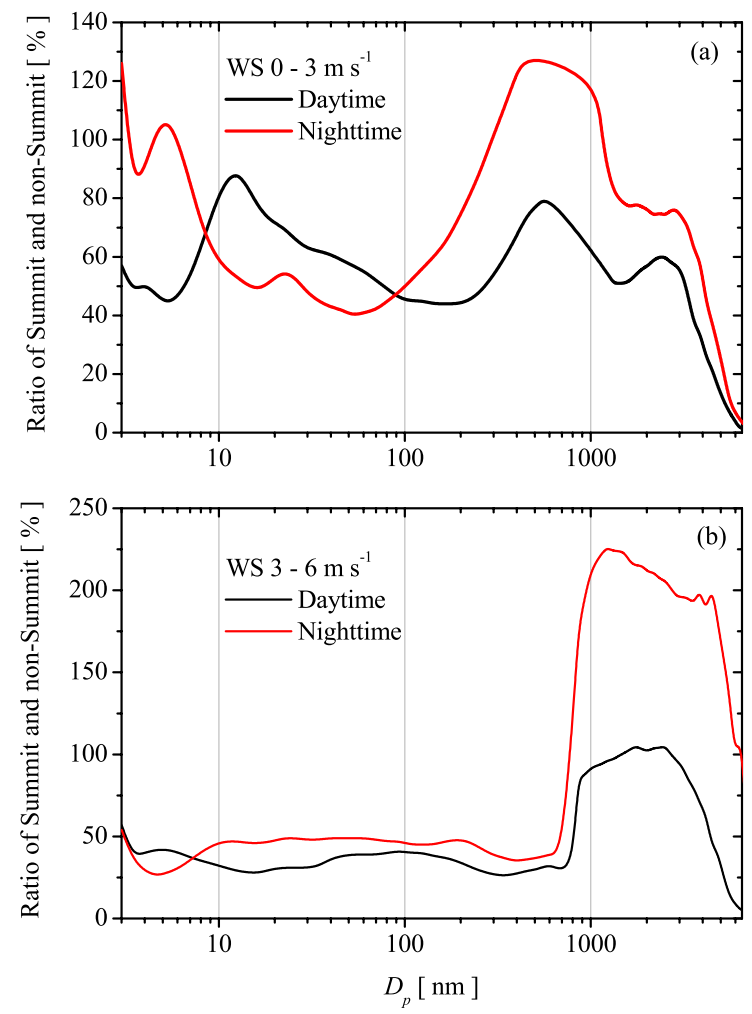

Fig. 4. Ratio of particle number concentrations between Summit and non-Summit time periods in daytime and nighttime for two wind classes of (a) $0-3 \mathrm{~m} \mathrm{~s}^{-1}$ and (b) $3-6 \mathrm{~m} \mathrm{~s}^{-1}$.

urnal variation of aerosol particle concentrations which usually accumulate during nighttime due to the lower boundary layer and reduced vertical mixing at night. Concerning the effect of the traffic restriction measures during Summit, we also calculated the ratio of particle number concentration at each diameter between Summit and non-Summit for daytime and nighttime for each wind class. The results are shown in Fig. 4. As expected, we do see a relatively stronger reduction in the Aitken and accumulation modes during daytime than that during nighttime in the wind class of $3-6 \mathrm{~m} \mathrm{~s}^{-1}$. In the low wind speed class $\left(0-3 \mathrm{~m} \mathrm{~s}^{-1}\right)$, stronger reduction during daytime was found for particles with diameters larger than about $90 \mathrm{~nm}$.

\section{Influence of the traffic restriction measures on visibil- ity}

Pollution by particulate matter is considered to be one of the most formidable air quality and public health issue in Beijing. The public expresses strong concerns about a decrease in "blue sky" days. "Blue sky" is closely related to the visual range, which is also one of the thorniest issues for the Olympics in Beijing 2008. 
Table 3. Simulated optical parameters of particle and gas phases at $550 \mathrm{~nm}$, as well as the visual ranges during Summit and non-Summit periods.

\begin{tabular}{|c|c|c|c|c|}
\hline & \multicolumn{2}{|c|}{$0-3 \mathrm{~m} \mathrm{~s}^{-1}$} & \multicolumn{2}{|c|}{$3-6 \mathrm{~ms}^{-1}$} \\
\hline & Summit & non-Summit & Summit & non-Summit \\
\hline \multicolumn{5}{|c|}{ Extinction of particle Phase $\left[\mathrm{Mm}^{-1}\right]$} \\
\hline Sub-1 $\mu \mathrm{m}$ & 340 & 410 & 19 & 53 \\
\hline Super-1 $\mu \mathrm{m}$ & 11 & 18 & 5.5 & 3.5 \\
\hline Total & 350 & 430 & 24 & 57 \\
\hline \multicolumn{5}{|c|}{ Extinction of gas phase $\left[\mathrm{Mm}^{-1}\right]$} \\
\hline Rayleigh scattering & 12 & 12 & 12 & 12 \\
\hline $\mathrm{NO}_{2}$ absorption & 9.2 & 13 & 9.2 & 13 \\
\hline Total & 21 & 25 & 21 & 25 \\
\hline Visual Range [km] & 5.2 & 4.2 & 42 & 23 \\
\hline
\end{tabular}

Since no qualified visibility observation was available, the improvement of visibility due to the traffic restriction measures has been estimated based on the light extinction of particle and gas phases. The average relative humidities of Summit and non-Summit periods were about $21 \%$ and $34 \%$, respectively. Particle hygroscopic growth factor at $\mathrm{RH} 40 \%$ in Beijing could only reach up to 1.01 in the winter time and the particles did not show obvious growth below RH $60 \%$ (J. Meier ${ }^{1}$, personal communication, 2005). So particle number size distributions under dry conditions $(\mathrm{RH}<30 \%)$ were used to simulate the particle extinction coefficients $\left(\sigma_{e p}\right)$ with a spherical Mie model (Bohren and Huffman, 1998). An effective medium refractive index was assumed as 1.52$0.025 i$. A time series of the optical equilibrium effective refractive indices was derived from an aerosol optical closure study based on in-situ intensive observations in January 2005 at the PKU site. 1.52-0.025i was an average of the retrieved values which resulted in an optimum fit between the measured and simulated particle scattering and absorption coefficients. According to the formulae introduced by Fröhlich and Shaw (1980) and Tomasi et al. (2005), the average Rayleigh scattering coefficients of gases $\left(\sigma_{s g}\right)$ has been estimated to be about $12 \mathrm{Mm}^{-1}$ for both Summit and nonSummit periods according to the recorded ambient temperature and pressure. Absorption of visible light by gases $\left(\sigma_{a g}\right)$ is considered to be essentially due to $\mathrm{NO}_{2}$ (Groblicki et al., 1981). The average concentration level of $\mathrm{NO}_{2}$ in Beijing during winter time was estimated to about $40 \mathrm{ppb}$ according to the $\mathrm{NO}_{2}$ concentrations measured with a long-path

\footnotetext{
${ }^{1}$ J. Meier, Modeling Department of Leibniz-Institute for Tropospheric Research, 04318 Leipzig, Germany, jmeier@tropos.de
}

absorption spectrometer (Qin et al., 2006) in the intensive measurement at the PKU site during January and February 2007 (Zhang and $\mathrm{Su}, 2007$ ). Therefore, $\sigma_{s g}$ at $550 \mathrm{~nm}$ was calculated to be about $13 \mathrm{Mm}^{-1}$ for non-Summit period with $\sigma_{a g}=0.33 \times\left[\mathrm{NO}_{2}\right]($ Groblicki et al., 1981). For the Summit period, a $40 \%$ reduction of $\mathrm{NO}_{\mathrm{x}}$ was reported by Wang et al (2007), associated with the $30 \%$ vehicles taking off the road. If we assume that there was also about $30 \%$ reduction of $\mathrm{NO}_{2}$ concentration during Summit, compared with the concentration of $40 \mathrm{ppb}$ during non-Summit period, the absorption of $\mathrm{NO}_{2}$ at $550 \mathrm{~nm}$ during Summit would be about $9.2 \mathrm{Mm}^{-1}$. The calculated optical parameters of particle and gas phases are summarized in Table 3. It is worth noticing that when wind speed lower than $3 \mathrm{~m} \mathrm{~s}^{-1}$, over $95 \%$ particle extinction was contributed by the sub- $1 \mu \mathrm{m}$ particles. Still, with the wind speed within the range of $3-6 \mathrm{~m} \mathrm{~s}^{-1}$, submicrometer particles contributed about $78 \%$ and $93 \%$ to the total particle extinctions during Summit and non-Summit periods, respectively.

Consequently, an upper limit to the visibility $\left(L_{v}, \mathrm{~km}\right)$ can be estimated, using the total light extinction of particle and gas phases $\left(\sigma_{e}=\sigma_{e p}+\sigma_{s g}+\sigma_{a g}, \mathrm{Mm}^{-1}\right)$ and a modified Koschmieder relation of $L_{v}=1.9 \times 10^{3} / \sigma_{e}$ (Griffing, 1980; Husar et al., 2000; Schichtel et al., 2001; Carrico et al., 2003). The Koschmieder constant of 1.9 is about half of the standard value (3.92) (Seinfeld and Pandis, 1998). The factor of two reduction considers the fact that real visual targets are not black, that they are frequently too small in size, and that they are located only at quantized distances away from the observer (Griffing, 1980). Since the comparison of size distributions when wind speed higher than $6 \mathrm{~m} \mathrm{~s}^{-1}$ was not statistically significant, we only discuss here the influence 


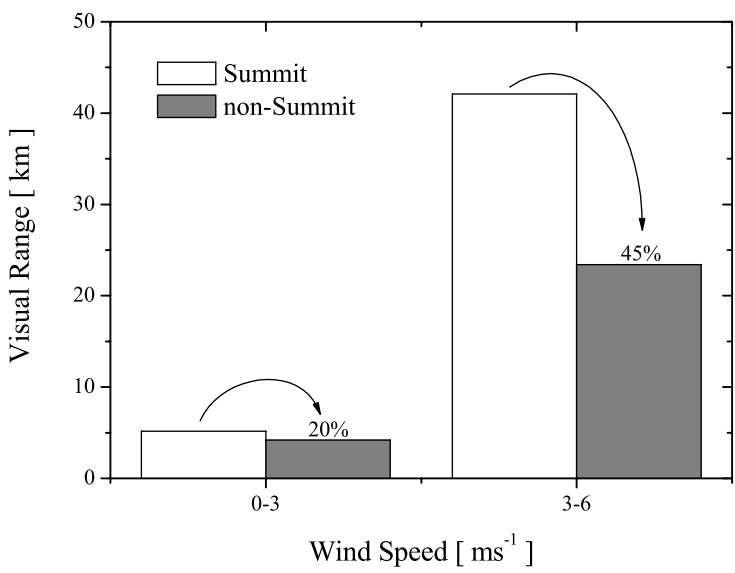

Fig. 5. Estimated visual range due to the extinction of particle and gas phases during Summit and non-Summit periods.

on the visibility by traffic restriction measures for the cases when wind speed was lower than $6 \mathrm{~m} \mathrm{~s}^{-1}$.

The estimated average visual ranges during Summit and non-Summit periods are presented in Table 3 and Fig. 5 for the wind classes of $0-3$ and $3-6 \mathrm{~m} \mathrm{~s}^{-1}$. Compared with non-Summit periods, improvements of visibilities during the Summit period were found. According to the estimate in Fig. 5, if no traffic restrictions had been in place during the Summit period, the average visual range during 4-6 November 2006 would have been lower by about $20 \%$ and $45 \%$ for wind classes of $0-3 \mathrm{~m} \mathrm{~s}^{-1}$ and $3-6 \mathrm{~m} \mathrm{~s}^{-1}$, respectively. We note that even with normal traffic on the road, when wind speed was higher than $3 \mathrm{~m} \mathrm{~s}^{-1}$, the visual range was over $20 \mathrm{~km}$ (cf. Fig. 5). We also applied this rough visibility estimate to the long-term particle number size distributions and found that over $95 \%$ cases with visual range lower than $5 \mathrm{~km}$ during 2004 to 2007 occurred when the local wind speed was lower than $3 \mathrm{~m} \mathrm{~s}^{-1}$. This may suggest that the importance of the emission restrictions is highest when the wind speed is lower than $3 \mathrm{~m} \mathrm{~s}^{-1}$, concerning the improvement of serious low visibility situations in Beijing.

\section{Conclusion and remarks}

We conclude that traffic restrictions implemented during the Sino-African Summit were successful in reducing the number concentration of aerosol particles, in particular Aitken and accumulation mode particles, and in improving the visibility. Concerning the important roles of atmospheric particles in public health, atmospheric heterogeneous chemistry and radiative forcing, as well as the emissions of $\mathrm{NO}_{\mathrm{x}}$ and volatile organic compounds which are essential controllers of lower tropospheric ozone, traffic restrictions could be effective in improving the air quality in Beijing and surrounding areas.
The influence of traffic restrictions in Beijing on the particle concentrations differs for different particle sizes. More significant effects on fine particles with diameters ranging from 40 to $500 \mathrm{~nm}$ have been found. Based on statistical analysis of long-term observation, under certain weather conditions, the source strength of the particles in Aitken and accumulation modes was reduced by $20-60 \%$ during the period of 4 to 6 November 2006, when the traffic restrictions were in place. This may be mainly due to the reduction of the secondary particle contributions to the fine aerosol particles. However, it is worth to notice that the reduction of $60 \%$ might overestimate the effect of the measures of traffic control, due to the inherent data shortage with very high wind speeds during the non-Summit period. We note that our sizedependent aerosol data indicate that current measures led to reductions in particulate air pollution in the optically most important size range, whereas further vehicle restriction measures may lead to an increase in ultrafine particle formation if the condensational sink decreased further. Because other than northerly wind specific discussed in the present study, particle formation events can happen with much higher condensational sink (0.02-0.08 s $\left.\mathrm{s}^{-1}\right)$ and lower wind speed if the air mass is mainly coming from the south of Beijing (Wu et al., 2007).

If we assume that there were no traffic restrictions taking place and with normal level of the vehicle emissions during the Summit period, the visibilities during 4-6 November 2006 would have been lower by about $20-45 \%$. The fact that over $95 \%$ cases with visibility range lower than $5 \mathrm{~km}$ during 2004 to 2007 occurred when the local wind speed was lower than $3 \mathrm{~m} \mathrm{~s}^{-1}$ may suggest that the importance of the emission restrictions is highest when the wind speed is lower than $3 \mathrm{~m} \mathrm{~s}^{-1}$, concerning the improvement of serious low visibility situations in Beijing.

This case study focused on the relative influence of traffic restrictions on particle size distribution and visibility, thus the uncertainties of the quantified effects are not expected to influence significantly conclusions drawn from the present statistical analysis. We emphasize, however, that specific weather conditions (a dominating wind direction from the north and northwest) governed the Summit period. Under these conditions, the local source of the Beijing city dominates, since air masses imported from the north are relatively clean (Wehner et al., 2008); whereas when air masses from the south or southeast carrying regional pollution have much stronger influence on the air quality in Beijing (Garland et al., 2008; Wehner et al., 2008).

The vehicle emission standard is improving in Beijing, and the new National IV standard implemented on 1 March 2008 is similar to Euro IV standard (XINHUA-NEWS, 2008). However, new car registrations in Beijing keep growing by about $11-12 \%$ annually since 2000 . A continuation of this increase may still cause intractable air quality problem in Beijing and its surrounding area in the near future. Multiple measures have been applied during the Olympic Game 
in 2008 to improve the air quality in Beijing, including controls on traffic and other sources. Coordinated observations of multiple atmospheric species combined with satellite remote sensing, and modeling studies during the Olympic may provide unique opportunities to further validate and improve our understanding of atmospheric chemistry and physics not only for Beijing area but also for the large region of northeastern China even East Asia (Wang et al., 2007), and it will support implementing strategies to cope with the air pollution in Beijing.

Acknowledgements. This work is supported by the Deutsche Forschungsgemeinschaft (DFG, WI 1449/9-1), the National Natural Science Foundation of China (20420130348), and the National Basic Research Program (2002CB211605, from the Ministry of Sciences \& Technology, China). The authors gratefully acknowledge the model support provided by NOAA through the availability of their meteorological fields and trajectory calculations with their HYSPLIT model.

Edited by: C. Chan

\section{References}

Birmili, W., Stratmann, F., and Wiedensohler, A.: Design of a DMA-based size spectrometer for a large particle size range and stable operation, J. Aerosol Sci., 30, 4, 549-553, 1999.

Birmili, W., Nowak, A., Schwirn, K., Lehmann, K., Massling, A., and Wiedensohler, A.: A new method to accurately relate dry and humidified number size distributions of atmospheric aerosols, J. Aerosol Sci., 1, 15-16, 2004.

Bohren, C. F. and Huffman, D. R.: Absorption and scattering of light by small particles, John Wiley \& Sons, Inc., 1998.

Carrico, C. M., Bergin, M. H., Xu, J., Baumann, K., and Maring, H.: Urban aerosol radiative properties: measurements during the 1999 Atlanta Supersite Experiment, J. Geophys. Res., 108, D78422, doi:10.1029/2001JD001222, 2003.

China-Daily: Beijing previews Olympic traffic plans during ChinaAfrica Summit: http://www.chinadaily.com.cn/2008/2006-11/ 07/content_726767.htm, 2006.

Duan, F., Liu, X., Yu, T., and Cachier, H.: Identification and estimate of biomass burning contribution to the urban aerosol organic carbon concentration in Beijing, Atmos. Environ., 38, 1275-1282, 2004.

Engler, C., Rose, D., Wehner, B., Wiedensohler, A., Brüggemann, E., Gnauk, T., Spindler, G., Tuch, T., and Birmili, W.: Size distributions of non-volatile particle residuals $(\mathrm{Dp}<800 \mathrm{~nm})$ at a rural site in Germany and relation to air mass origin, Atmos. Chem. Phys., 7, 5785-5802, 2007,

http://www.atmos-chem-phys.net/7/5785/2007/.

Fröhlich, C. and Shaw, G. E.: New determination of Rayleigh scattering in the terrestrial atmosphere, Appl. Opt., 19, 11, 1773$1775,1980$.

Garland, R. M., Schmid, O., Gunthe, S. S., Nowak, A., Wiedensohler, A., Hu, M., Shao, M., Zeng, L., Zhu, T., Andreae, M. O., and Pöschl, U.: Aerosol optical properties observed during CAREBEIJING-2006: Characteristic differences between the in- flow and outflow of Beijing city air, J. Geophys. Res., in review, 2008.

Griffing, G. W.: Relations between the prevailing visibility, nephelometer scattering coefficient and sunphotometer turbidity coefficient, Atmos. Environ., 14, 577-584, 1980.

Groblicki, P. J., Wolff, G. T., and Countess, R. J.: Visibilityreduction species in the Denver "Brown Cloud" - I. Relationships between extinction and chemical composition, Atmos. Environ., 12, 2437-2484, 1981.

He, K., Yang, F., Ma, Y., Zhang, Q., Yao, X., Chan, C. K., Cadle, S., Chan, T., and Mulawa, P.: The characteristics of $\mathrm{PM}_{2.5}$ in Beijing, China, Atmos. Environ., 35, 4959-4970, 2001.

Husar, R. B., Husar, J. D., and Martin, L.: Distribution of continental surface aerosol extinction based on visual range data, Atmos. Environ., 34, 5067-5078, 2000.

Imhof, D., Weingartner, E., Prévôt, A. S. H., Ordóñez, C., Kurtenbach, R., Wiesen, P., Rodler, J., Sturm, P., McCrae, I., Ekstr'om, M., and Baltensperger, U.: Aerosol and $\mathrm{NO}_{\mathrm{x}}$ emission factors and submicron particle number size distributions in two road tunnels with different traffic regimes, Atmos. Chem. Phys., 6, 22152230, 2006, http://www.atmos-chem-phys.net/6/2215/2006/.

Janhäll, S., Johsson, Å. M., Molnár, P., Svensson, E. A., and Hallquist, M.: Size resolved traffic emission factors of submicrometer particles, Atmos. Environ., 38, 4331-4340, 2004.

Kulmala, M., Laaksonen, A., and Pirjola, L.: Parameterizations for sulfuric acid/water nucleation rates, J. Geophys. Res., 103(D7), 8301-8307, 1998.

Moussiopoulos, M., Sahm, P., Kunz, R., Vögele, T., Schneider, C., and Kessler, C.: High resolution simulations of the wind flow and the ozone formation during the Heilbronn ozone experiment, Atmos. Environ., 31(19), 3177-3186, 1997.

Pirjola, L., Laaksonen, A., Aalto, P., and Kulmala, M.: Sulfate aerosol formation in the Arctic boundary layer, J. Geophys. Res., 103(D7), 8309-8321, 1998.

Qin, M., Xie, P.-h., Liu, W.-q., Li, A., Dou, K., Fang, W., Liu, J.-g., and Zhang, W.-j.: Observation of atmospheric nitrous acid with DOAS in Beijing, China, J. Envrion. Sci., 18(1), 69-75, 2006.

Rose, D., Wehner, B., Ketzel, M., Engler, C., Voigtländer, J., Tuch, T., and Wiedensohler, A.: Atmospheric number size distributions of soot particles and estimation of emission factors, Atmos. Chem. Phys., 6, 1021-1031, 2006,

http://www.atmos-chem-phys.net/6/1021/2006/.

Schichtel, B. A., Husar, R. B., Falke, S. R., and Wilson, W. E.: Haze trends over the United States, 1980-1995, Atmos. Environ., 35, 5205-5210, 2001.

Seinfeld, J. and Pandis, S.: Atmospheric chemistry and physics, John Wiley \& Sons, Inc., New York, 1326 pp., 1998.

Song, Y., Zhang, Y., Xie, S., Zeng, L., Zheng, M., Salmon, L. G., Shao, M., and Slanina, S.: Source apportionment of $\mathrm{PM}_{2.5}$ in Beijing by positive matrix factorization, Atmos. Environ., 40, 1526-1537, 2006.

Tomasi, C., Vitale, V., Petkov, B., Lupi, A., and Cacciari, A.: Improved algorithm for calculations of Rayleigh-scattering optical depth in standard atmospheres, Appl. Opt., 44, 16, 3320-3341, 2005.

Travis, D. J., Carleton, A. M., and Lauritsen, R. G.: Contrails reduce daily temperature range, Nature, 418, 601, 2002.

Wang, Y., McElroy, M. B., Boersma, K. F., Eskes, H. J., and 
Veefkind, J. P.: Traffic restrictions associated with the SinoAfrican summit: Reductions of $\mathrm{NO}_{\mathrm{x}}$ detected from space, Geophys. Res. Lett., 34, L08814, doi:10.1029/2007GL029326, 2007.

Wehner, B., Bond, T. C., Birmili, W., Bussemer, M., Heintzenberg, J., Wiedensohler, A., and Charlson, R. J.: Climate-relevant particulate emission characteristics of a coal fired heating plant, Environ. Sci. Techol., 33(21), 3881-3886, 1999.

Wehner, B., Birmili, W., Gnauk, T., and Wiedensohler, A.: Particle number size distributions in a street canyon and their transformation into the urban background: Measurements and a simple model study, Atmos. Environ., 26(13), 2215-2223, 2002.

Wehner, B. and Wiedensohler, A.: Long term measurements of submicrometer urban aerosols: statistical analysis for correlations with meteorological conditions and trace gases, Atmos. Chem. Phys., 3, 867-879, 2003, http://www.atmos-chem-phys.net/3/867/2003/.

Wehner, B., Wiedensohler, A., Tuch, T. M., Wu, Z. J., Hu, M., Slanina, J., and Kiang, C. S.: Variability of the aerosol number size distribution in Beijing, China: New particle formation, dust storm, and high continental background, Geophys. Res. Lett., 31, L22108, doi:10.1029/2004GL021596, 2004.

Wehner, B., Birmili, W., Ditas, F., Wu, Z., Hu, M., Liu, X., Mao, J., Sugimoto, N., and Wiedensohler, A.: Relationships between submicrometer particulate air pollution and air mass history in Beijing, China, 2004-2006, Atmos. Chem. Phys., 8, 6155-6168, 2008, http://www.atmos-chem-phys.net/8/6155/2008/.

Willeke, K. and Baron, P. A.: Aerosol measurement: Principles, techniques, and applications, Van Nostrand Reinhold, New York, USA, 1993.

Wu, Z., Hu, M., Liu, S., Wehner, B., Bauer, S., Maßling, A., Wiedensohler, A., Petäjä, T., Maso, M. D., and Kulmala, M.: New particle formation in Beijing, China: Statistical analysis of a 1-year data set, J. Geophys. Res., 112, D09209, doi:10.1029/2006JD007406, 2007.
Wu, Z., Hu, M., Lin, P., Liu, S., Wehner, B., and Wiedensohler, A.: Particle number size distribution in the urban atmosphere of Beijing, China, Atmos. Environ., 42, 34, 7967-7980, doi:10.1016/j.atmosenv.2008.06.022, 2008.

Xia, X., Eck, T. F., Holben, B. N., Phillippe, G., and Chen, H.: Analysis of the weekly cycle of aerosol optical depth using AERONET and MODIS data, J. Geophys. Res., 113, D14217, doi:10.1029/2007JD009604, 2008.

Xie, S. D., Liu, Z., Chen, T., and Hua, L.: Spatiotemporal variations of ambient $\mathrm{PM}_{10}$ source contributions in Beijing in 2004 using positive matrix factorization, Atmos. Chem. Phys., 8, 27012716, 2008, http://www.atmos-chem-phys.net/8/2701/2008/.

XINHUA-NEWS: Implementation of National VI vehicle emission standard on 1 January 2008 in Beijing: http://news.xinhuanet. com/auto/2008-02/15/content_7609678.htm, 2008 (in Chinese).

Zhang, Y. H. and Shao, M.: Air quality in Beijing and its transition from coal burning caused problems to traffic exhaust related pollution, 90th Annual Meeting of Air \& Waste Management Association (97-TP67.07), Toronto, Canada, 1997.

Zhang, Y. H. and Su, H.: Concentation and budget of HONO and its important role in atmosheric photochemistry in Beijing, Report to China National Natural Science Foundation (40675072 (D0510)), College of Environmental Sciences and Engineering, Peking University, Beijing 40675072(D0510), 5, 2007.

Zheng, M., Salmon, L. G., Schauer, J. J., Zeng, L., Kiang, C. S., Zhang, Y., and Cass, G. R.: Seasonal trends in $\mathrm{PM}_{2.5}$ sources contributions in Beijing, China, Atmos. Environ., 39, 39673976, 2005. 